\title{
Influencing the Crystallization of Glass-Ceramics by Ultrashort Pulsed Laser Irradiation after Nucleation
}

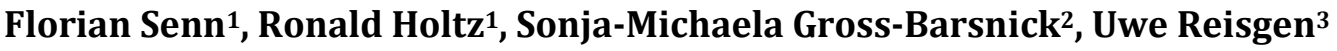 \\ ${ }^{1}$ Institute of Product and Production Engineering-IPPE, FHNW Technik, Windisch, Switzerland \\ ${ }^{2}$ Central Institute of Engineering, Electronics and Analytics-ZEA, Forschungszentrum Jülich GmbH, Jülich, Germany \\ ${ }^{3}$ Welding and Joining Institute-ISF, RWTH Aachen University, Aachen, Germany \\ Email: florian.senn@fhnw.ch
}

How to cite this paper: Senn, F., Holtz, R., Gross-Barsnick, S.-M. and Reisgen, U. (2018) Influencing the Crystallization of Glass-Ceramics by Ultrashort Pulsed Laser Irradiation after Nucleation. New Journal of Glass and Ceramics, 8, 1-11.

https://doi.org/10.4236/njgc.2018.81001

Received: November 28, 2017

Accepted: January 7, 2018

Published: January 10, 2018

Copyright $\odot 2018$ by authors and Scientific Research Publishing Inc. This work is licensed under the Creative Commons Attribution International License (CC BY 4.0).

http://creativecommons.org/licenses/by/4.0/

\begin{abstract}
An ultra-fast laser with central wavelength at $1064 \mathrm{~nm}$ and $10 \mathrm{ps}$ pulse duration was used to tightly focus laser radiation with a microscope objective inside the volume of nucleated Lithium Aluminosilicate (LAS) glass-ceramic. The nonlinear absorption of the LAS glass-ceramic was measured for different laser parameters and a thermal simulation was performed to determine the temperature field inside the laser-modified area. After laser processing, the samples were crystallized in a furnace and the effect of the laser-induced modifications on the microstructure was analyzed with SEM. The SEM analysis shows an increase in the length and size of whisker-shaped $\beta$-spodumene crystals in the laser-modified area. By increasing the dimension of these whisker-shaped crystals, the flexural strength of LAS can be improved locally. First four-point bending flexural tests were performed to examine the influence on the mechanical properties.
\end{abstract}

\section{Keywords}

Glass-Ceramics, Microstructure, Nonlinear Absorption, Picosecond Laser

\section{Introduction}

One advantage of laser radiation is the possibility to deposit energy on a very small and well defined area. This effect was used in [1] to show the feasibility of gradual and partial crystallization of glass-ceramics using continuous wave (CW) laser radiation. Due to the use of $\mathrm{CW}$ laser radiation, the crystallization process could only be started from the body surface. 
Tight focusing of ultrashort-pulsed (USP) laser radiation enables the deposition of energy inside the volume of transparent dielectrics. Thereby it is possible to generate local material modifications on the micro and nanometer scale in the bulk material. If the intensity $I$ of the laser radiation is sufficiently high, energy can be absorbed due to the effects of nonlinear absorption (NLA). Heat transfer from the electrons to the lattice then results in material modifications [2]. Depending on the laser parameters like pulse width $\tau_{\text {Pulse }}$, pulse repetition frequency (PRF) $f_{\text {Pulse }}$, pulse energy $E_{\text {Pulse }}$ and the optical and thermal properties of the dielectric, different temperatures emerge in the focal area. This leads to various effects like void formation, change of the birefringent index or the production of micro cracks.

Since the development of industrial femto second lasers, many interesting applications have evolved based on the effect of NLA. Examples which involve the change of the birefringent index are writing of waveguides [3] or data storage with 3D Bit Arrays [4]. Another application of NLA is the production of microfluidic devices. By treating photosensitive glass with laser radiation, complex 3D structures can be produced inside the bulk material and microfluidic channels can be etched in a second step [5]. Finally, NLA is used in the micro machining field for laser welding of two overlapping glass plates at their interface through the first plate [6].

In this paper, NLA induced thermal treatment by picosecond laser irradiation at $1064 \mathrm{~nm}$ wavelength of Lithium Aluminosilicate (LAS) glass-ceramic in the nucleated state is discussed. By destroying the crystallization seeds or changing their distribution, the microstructure after the crystallization in the furnace can be modified locally. The modification of the material is related to calculated temperature distributions. Finally, the impact of the treatment on the flexural strength of the LAS glass-ceramic is discussed.

\section{Experimental Setup}

\subsection{Laser System}

The setup for the irradiation experiments is illustrated in Figure 1. A picosecond laser with central wavelength at $1064 \mathrm{~nm}, 10 \mathrm{ps}$ pulse duration and a variable pulse repetition rate from $50 \mathrm{kHz}$ to $8.2 \mathrm{MHz}$ was used. A pulse on demand module enabled the pulse picking. The beam expander with a magnification of two was necessary to reduce the power density on the mirrors and in the objective. The beam was focused with a microscope objective with a NA of 0.4. The theoretical radius in the focal plane of the beam $\omega_{0}$ in air was calculated [7]:

$$
\omega_{0}=M^{2} \frac{\lambda}{\pi N A} .
$$

where $M^{2}$ is the beam quality factor, $\lambda$ is the wavelength and $N A$ is the numerical aperture. Calculated for this laser system with a $M^{2}<1.1$, the focal radius is approximately $0.9 \mu \mathrm{m}$. 
The sample was moved by a CNC controlled axis system in all three dimensions. A power meter was mounted on the backside of the sample to measure the power transmitted through the sample.

\subsection{Lithium Aluminosilicate Glass-Ceramic Samples}

The glass-ceramic examined in this paper belongs to the $\mathrm{Li}_{2} \mathrm{O}-\mathrm{Al}_{2} \mathrm{O}_{3}-\mathrm{SiO}_{2}$ (LAS) System and is described in [8]. The experiments presented in this work were all performed in the nucleated state, reached after a 30 minutes long treatment in the furnace at $660^{\circ} \mathrm{C}$. The measured material properties of the examined LAS glass-ceramic samples can be found in Table 1 for all three states.

To prevent surface absorption related to physical imperfections like grooves, scratches, cracks or pores [9], the samples were polished. For the NLA characterization, plates with a size of $3 \times 30 \times 83 \mathrm{~mm}$ were used. The samples for the four-point bending flexural test had a dimension of $3 \times 4 \times 43 \mathrm{~mm}$.

\section{Nonlinear Absorption}

Because of the high band gap energy $E_{\mathrm{G}}$ of multiple $\mathrm{eV}$, absorption in LAS glass-ceramic of $1064 \mathrm{~nm}$ laser irradiation $\left(E_{\text {Photon }} \approx 1 \mathrm{eV}\right)$ cannot be explained by linear electron-photon interaction. A single photon with $1064 \mathrm{~nm}$ wavelength

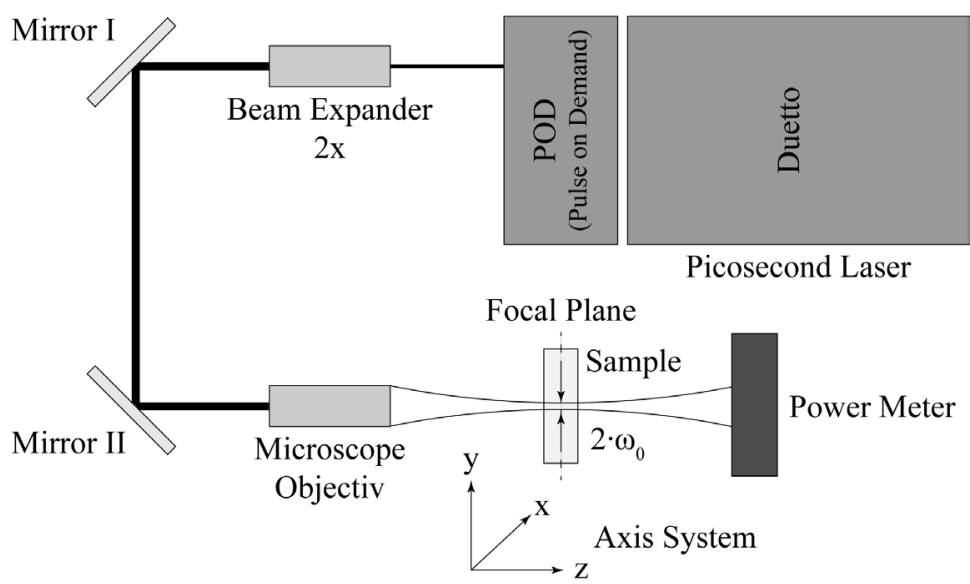

Figure 1. Experimental setup for the production of laser-induced modifications inside LAS.

Table 1. Properties of the examined Lithium Aluminosilicate glass-ceramic in all three states.

\begin{tabular}{lccccc}
\hline & & & Glass state & Nucleated & Crystallized \\
\hline $\begin{array}{l}\text { Density } \\
\begin{array}{l}\text { Flexural strength } \\
\text { (DIN EN ISO 6872) }\end{array}\end{array}$ & $\sigma$ & $\mathrm{g} / \mathrm{cm}^{3}$ & 2.51 & - & - \\
$\begin{array}{l}\text { Fracture toughness } \\
\text { (ISO 23146) }\end{array}$ & $K_{\mathrm{IC}}$ & $\mathrm{MPam}^{1 / 2}$ & $0.72 \pm 0.02$ & $0.90 \pm 0.10$ & $1.72 \pm 0.13$ \\
\begin{tabular}{l} 
Refractive index \\
\hline
\end{tabular} & $n$ & - & 1.52 & 1.54 & - \\
\hline
\end{tabular}


has not enough energy to lift an electron from the valence band to the conduction band.

To enable a modification in LAS glass-ceramic, the density of electrons in the conduction band must reach $10^{19} \mathrm{~cm}^{-3}$ [10]. To reach these intensities the USP laser light was focused tightly by a microscope objective with high NA. The high intensity of the laser light enables a process where multiple photons stimulate the same electron simultaneously and lift it to the conduction band (multiphoton ionization). Consequently, electron plasma is formed in the conduction band, which absorbs the laser energy very effectively (avalanche mechanism) and transfers it to the lattice, heating it up. This process is described in [11].

\subsection{Absorption Curves of LAS}

To measure the absorption curves of LAS a sample was moved with constant speed of $20 \mathrm{~mm} / \mathrm{s}$ through the focus of the laser beam. The transmitted pulse energy $Q_{t}$ on the backside was measured with the power meter (Figure 1) and compared to the pulse energy $Q_{0}$ with no sample in between. The nonlinear absorption $A_{\exp }$ was calculated with [12]

$$
A_{\text {exp }}=1-\frac{Q_{t}}{Q_{0}} \frac{1}{\left(1-R^{2}\right)} .
$$

The parameter $R$ is the Fresnel reflectivity, which is calculated for the special case of perpendicular irradiation using

$$
R=\left(\frac{n_{1}-n_{2}}{n_{1}+n_{2}}\right)^{2},
$$

where $n_{1}$ is the refractive index of air and $n_{2}$ is the refractive index of nucleated LAS. The calculated value for $R$ with $n_{1}=1$ and $n_{2}=1.54$ is 0.045 . This means that $4.5 \%$ of the laser light will be reflected. Figure 2 shows the measured absorption curve for the LAS glass-ceramic in the nucleated state for different laser pulse energy and PRF values.

The maximum absorption is in the range of $40 \%$. If the PRF increases, the rate of NLA increases as well. The threshold intensity for visible laser-induced modifications was determined with $2.6 \times 10^{17} \mathrm{~W} / \mathrm{m}^{2}$ by using a light microscope. The smallest measured width of the modifications $\omega_{0}$ was determined with $0.35 \mu \mathrm{m}$, which is much less then theoretically calculated. This results in a threshold pulse energy of $2.1 \mu \mathrm{J}$.

\subsection{Absorbed Laser Power}

The laser-modified area $S_{\text {Mod }}$ has been measured by a light microscope on the polished surface in direction of axis movement. In Figure $3 S_{\text {Mod }}$ is plotted versus the overall absorbed laser power given by $W_{\mathrm{Ab}}$

$$
W_{A b}=A_{\text {exp }} \cdot f_{\text {Pulse }} Q_{0}=A_{\text {exp }} P_{\text {Avg }},
$$

where $P_{\mathrm{Avg}}$ is the measured laser power. A good correlation between the 


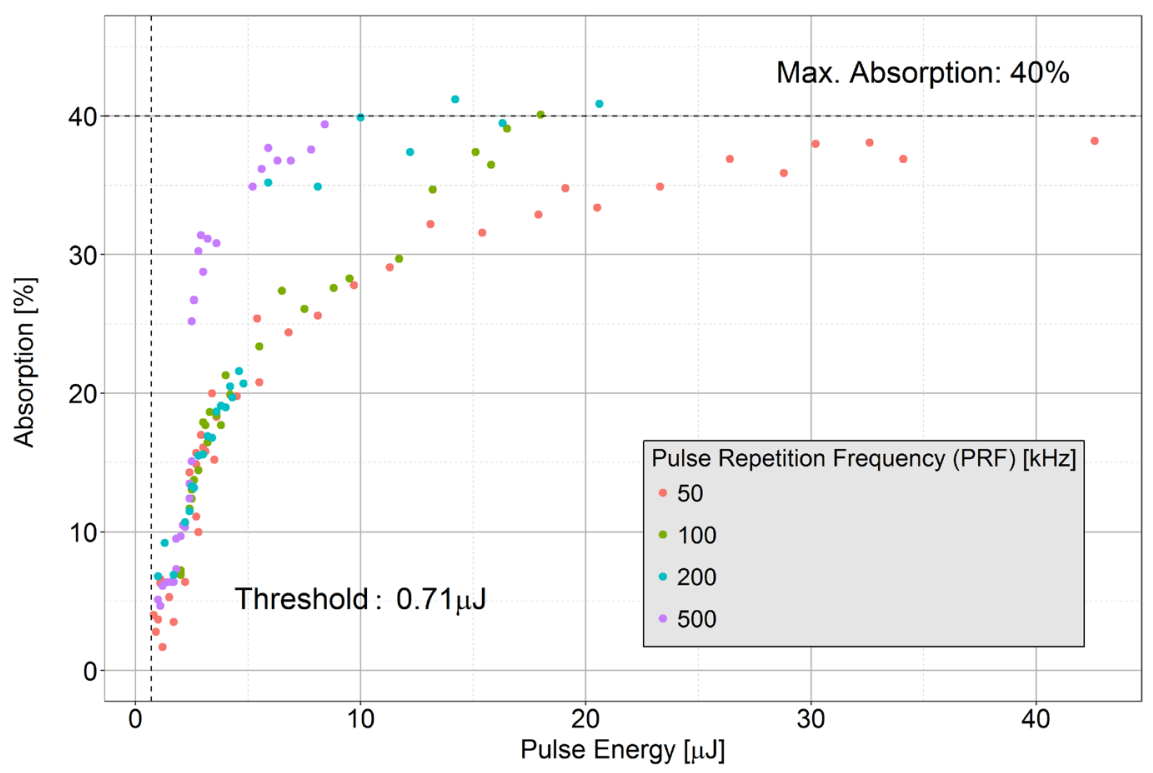

Figure 2. Experimental measurement of the nonlinear absorption of LAS.

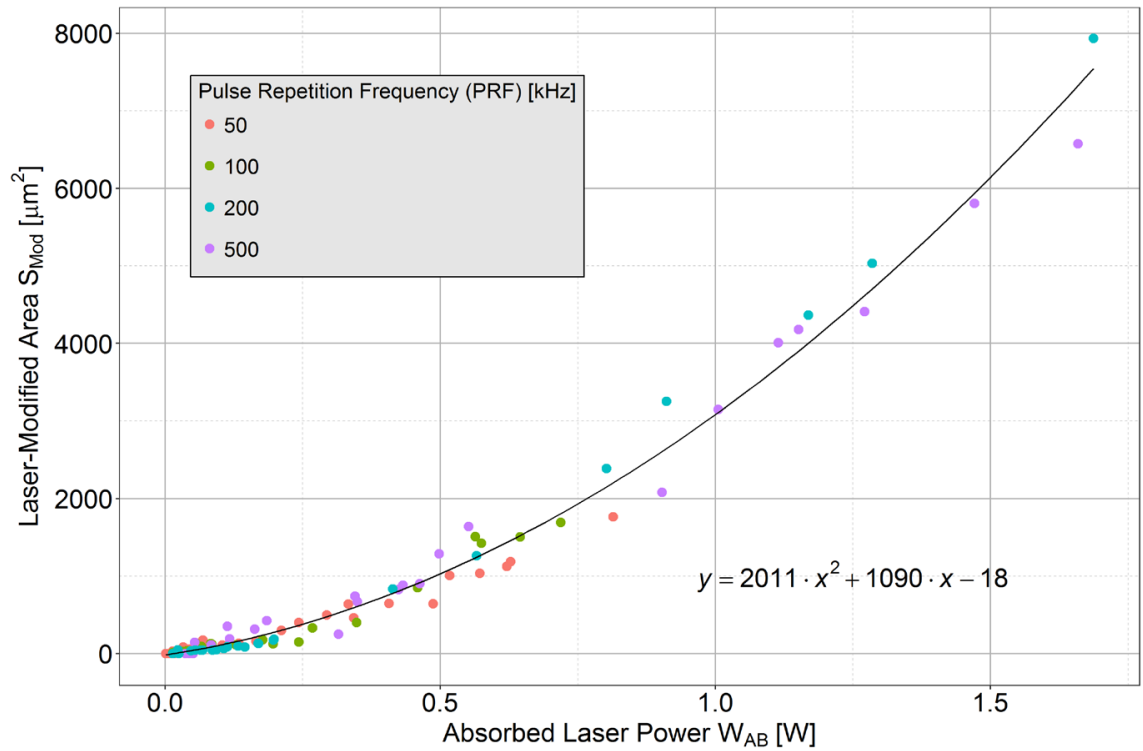

Figure 3. Laser-modified area $S_{\mathrm{Mod}}$ vs. absorbed laser power $W_{\mathrm{AB}}$ for the LAS glass-ceramic@20 mm/s sample speed.

laser-modified area $S_{\text {Mod }}$ and the absorbed laser power $W_{\mathrm{Ab}}$ can be found by fitting the data points using a polynomial function.

\section{Thermal Simulation}

\subsection{Model}

Thermal simulations of the irradiated region were performed to compare the material modifications with the calculated temperature profile. The laser induced modifications were simulated by a line heat source with a continuous heat delivery of $w(z)$ at $x=y=0$ over a defined length of $0<z<1$ in an infinite solid, 
which moves with a constant speed of $v_{\text {Axis }}$ along the $x$ axis. The temperature distribution $T(x, y, z)$ in a steady state with an initial temperature $T_{0}$ can be written using [13]

$$
T(x, y, z)=\frac{1}{4 \pi K} \int_{0}^{l} \frac{w\left(z^{\prime}\right)}{s} \exp \left\{-\frac{v_{A x i s}}{2 \alpha}(x+s)\right\} \mathrm{d} z^{\prime}+T_{0},
$$

where $s^{2}=x^{2}+y^{2}+(z-z)^{2}, K$ is the thermal conductivity and $\alpha$ the thermal diffusivity, which can be calculated by $K /(\rho \cdot c)$ where $\rho$ is the mass density and $c$ is the specific heat of the LAS glass-ceramic. The model used for the thermal simulation is illustrated in Figure 4.

The maximum temperature in the $y-z$ plane can be found where $\mathrm{d} T / \mathrm{d} x$ equals zero by solving

$$
\int_{0}^{l} \frac{w\left(z^{\prime}\right)}{s} \exp \left\{-\frac{v}{2 \alpha}(x+s)\right\}\left\{\frac{x}{r^{3}}-\frac{v}{2 \alpha}\left(\frac{x}{r}-1\right)\right\} \mathrm{d} z^{\prime}=0 .
$$

According to [14] $w(z)$ can be written as a simple function of $z$ given by

$$
w(z)=a z^{m}+b,
$$

where $a, b$ and $m$ are positive constants. By rearranging Equation (4) the calculated absorption $A_{\text {Calc }}$ can be written as follows:

$$
A_{\text {Calc }}=\frac{W_{A b}}{f Q_{0}} .
$$

Replacing $W_{\mathrm{Ab}}$ with the integral over $w(z)$ :

$$
A_{\text {Calc }}=\frac{1}{f Q_{0}} \int_{0}^{l} w(z) \mathrm{d} z .
$$

Solving Equation (9) analytically with the defined function of $w(z)$ in Equation (7) $A_{\text {Calc }}$ becomes

$$
A_{\text {Calc }}=\frac{1}{f Q_{0}}\left(\frac{a}{m+1} l^{m+1}+b l\right) .
$$

Now it is possible to fit $a, b$ and $m$. The length $l$ of the laser modified area was measured.
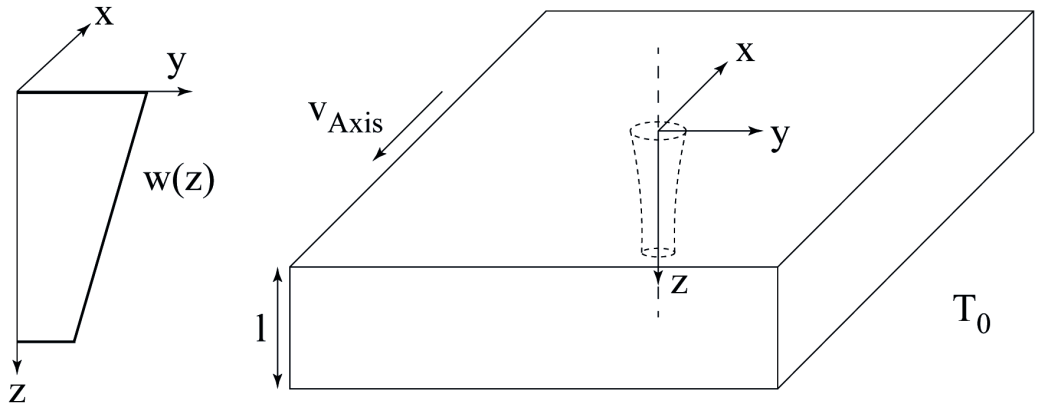

Figure 4. Model of a moving line heat source with heat delivery $w(z)$. 


\subsection{Results}

For a modification with a $f_{\text {Pulse }}$ of $50 \mathrm{kHz}$ and a speed of $V_{\text {Axis }}$ of $20 \mathrm{~mm} / \mathrm{s}$ an experimental absorption $A_{\mathrm{Ex}}$ of $40.4 \%$ was calculated. The pulse energy $Q_{0}$ was 41.2 $\mu \mathrm{J}$ and the length of the laser absorbed region was $151.8 \mu \mathrm{m}$. The values for $m=$ $1, a=4.9 \times 10^{7} \mathrm{~W} / \mathrm{m}^{2}$ and $b=1825 \mathrm{~W} / \mathrm{m}$ were taken and adapted from [14]. The absorption $A_{\text {Calc }}$ became $40.7 \%$.

Because no thermal data of nucleated LAS glass-ceramic were available, the values for conductivity and diffusivity were taken from soda-lime glass (SLG) [15] with $K=1.005 \mathrm{~W} /(\mathrm{m} \cdot \mathrm{K})$ and $\alpha=4.365 \times 10^{-7} \mathrm{~m}^{2} / \mathrm{s}$. The comparison of the calculated temperature distribution in the $y z$-plane and the polished cross-section of a modified region is shown in Figure 5 for $T_{0}=25^{\circ} \mathrm{C}$. The direction of the laser is along the z-axis in negative direction and the movement of the axis is perpendicular to the plane of the image.

By overlapping the isothermal line for the melting point of SLG (viscosity $\eta=$ $\left.10^{1} \mathrm{~Pa} \cdot \mathrm{s}\right)$ at $1400^{\circ} \mathrm{C}$ [16] on a picture of the cross-section of the laser-induced modification, the model shows a good convergence. The material inside the drop shaped area was exposed to temperatures higher than the melting point of LAS glass-ceramic. This could lead to a destruction or a displacement of the crystal seeds.

\section{Experiments}

\subsection{Laser-Induced Modifications}

Thirty flexural bending samples have been structured with five different parameter sets according to Figure 6. The exact values for every parameter set can be found in Table 2. The samples were mounted in a small vice and then moved through the laser focus by the CNC axis system.
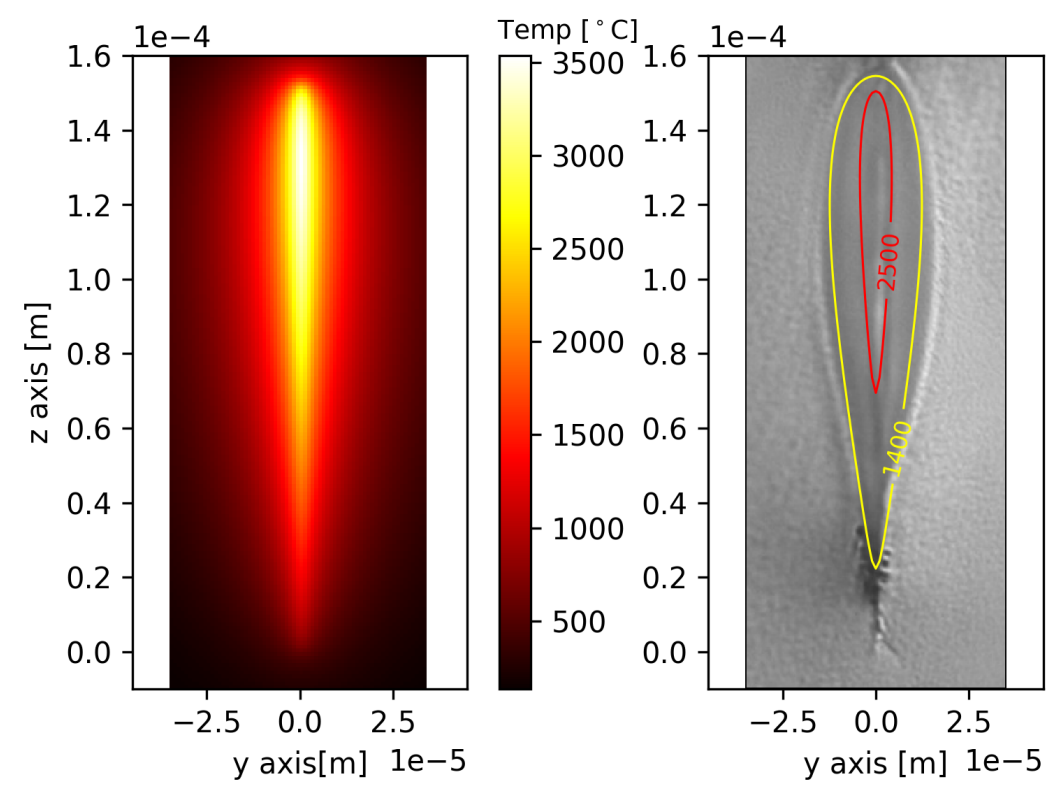

Figure 5. Simulation of the maximum cycle temperature with isothermal lines. 


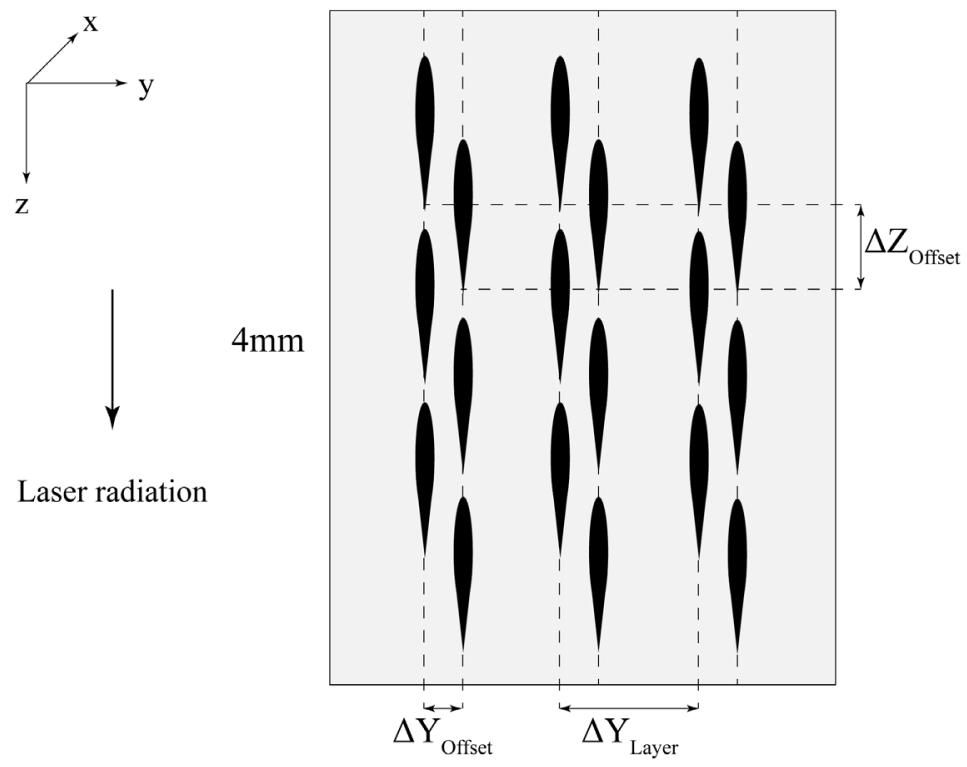

Figure 6. Laser-induced continuous modifications inside LAS glass-ceramic bending samples.

Table 2. Parameter settings for the laser treatment of the LAS samples.

\begin{tabular}{cccccccc}
\hline Nr. & Pcs. & $\Delta \mathrm{Y}_{\text {Layer }}$ & $\Delta \mathrm{Y}_{\text {Offset }}$ & $\Delta \mathrm{Z}_{\text {Offset }}$ & $Q_{0}$ & $V_{\text {Axis }}$ & $f_{\text {Pulse }}$ \\
\hline- & - & $\mu m$ & $\mu m$ & $\mu m$ & $\mu J$ & $m m / s$ & $k H z$ \\
1 & 6 & $160(\mathrm{~A} 1)$ & 80 & 80 & 10 & 20 & 50 \\
2 & 6 & $160(\mathrm{~A} 1)$ & 80 & 80 & 20 & 20 & 50 \\
3 & 6 & $120(\mathrm{~A} 1)$ & 60 & 80 & 20 & 20 & 50 \\
4 & 6 & $320(\mathrm{~A} 2)$ & 80 & 80 & 20 & 20 & 50 \\
5 & 6 & $320(\mathrm{~A} 2)$ & 80 & 80 & 30 & 20 & 50 \\
\hline
\end{tabular}

The feedrate $V_{\text {Axis }}$ and the pulse repetition frequency $f_{\text {Pulse }}$ have not been changed to analyze the influence of the pulse energy $Q_{0}$ and the density of the induced modifications. 13 samples have not been treated by laser but were crystallized with the same temperature profile to get a reference value.

\subsection{SEM Analysis after Crystallization}

Figure 7 shows a scanning electron microscopy (SEM) image of the polished and with hydrofluoric acid (HF) etched surface of the $x-y$ plane after the crystallization of the samples for 90 minutes at $820^{\circ} \mathrm{C}$. The microstructure reveals a network of needle-like (whisker-shaped) interlocked crystals embedded in the glassy matrix. A cross-section through a laser-induced modification is clearly visible in the middle of the image (between the dashed lines).

In the area of the laser-induced modification, the needle-like crystals are much longer and thicker. This effect could be caused either by destruction or displacement of the crystal seeds in the molten state. Both approaches would 


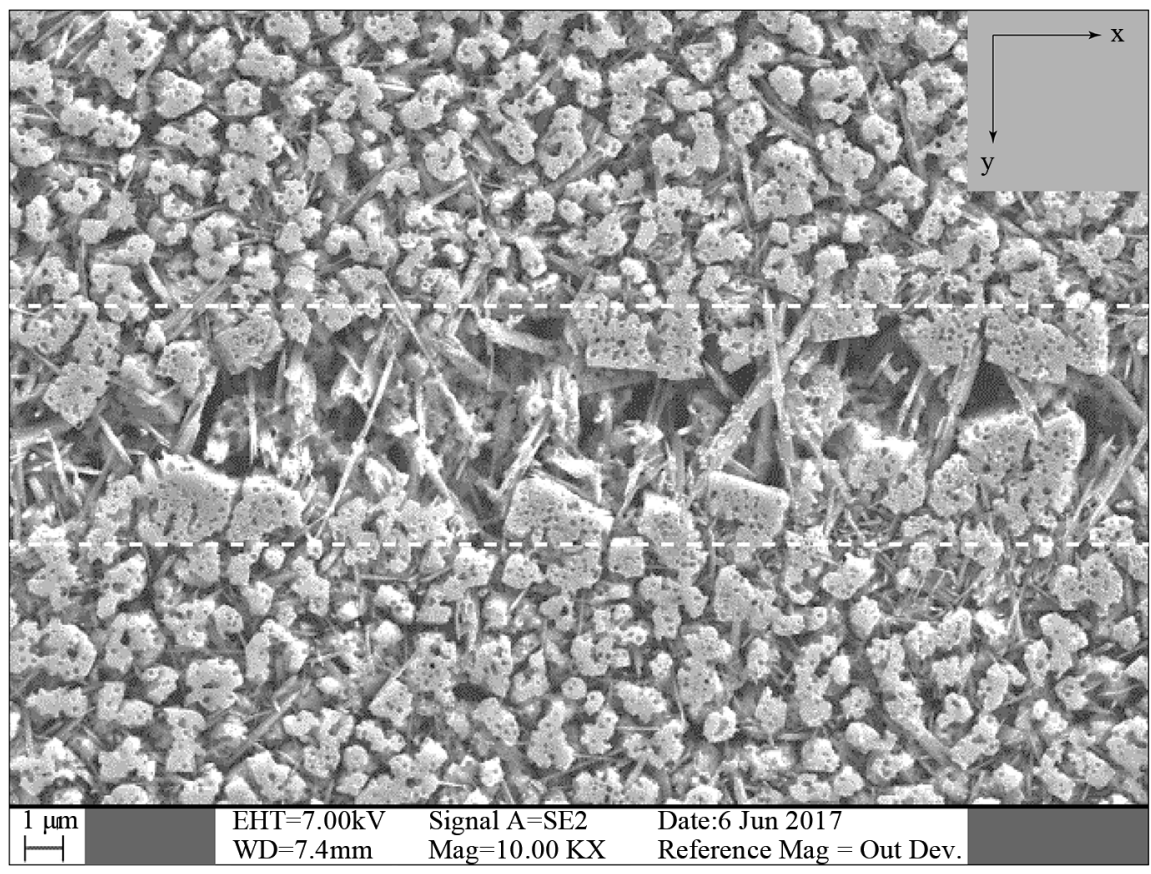

Figure 7. Laser-induced continuous modification inside LAS glass-ceramic $-\mathrm{v}_{\mathrm{Axis}}=20$ $\mathrm{mm} / \mathrm{s}, \mathrm{f}_{\text {Pulse }}=50 \mathrm{kHz}, Q_{0}=30 \mu \mathrm{J}$.

explain a reduced density of crystal seeds inside the laser treated area, which results in the growth of these longer and thicker crystals. The orientation of the crystals inside the laser treated area is more or less parallel to the y-axis. This leads to the hypothesis that the crystals grow from the interface between treated and untreated area.

Anmin et al. [17] have observed that an increase of the flexural strength depends on the size of these interlocked whisker-shaped $\beta$-spodumene crystals. By locally increasing the length and size of this $\beta$-spodumene crystal through laser radiation, an effect on the flexural strength is expected to be visible.

\subsection{Four-Point Bending Flexural Strength}

Figure 8 shows the single results of the four-point bending flexural strength tests according to DIN EN ISO 6872. For each parameter set the standard deviation around the mean value is indicated through error bars.

The results of the four-point bending flexural tests showed so far, that a laser treatment of nucleated samples is not increasing the average value significantly. A single sample of the group A1 reached a flexural strength of 295.2 Mpa. This effect suggests that a higher density of laser-induced modifications could increase the flexural strength.

\section{Conclusions}

It was possible to show that the treatment of nucleated LAS samples with USP laser radiation leads to a change in the microstructure after the crystallization process. A thermal simulation enabled an estimation of the temperature 


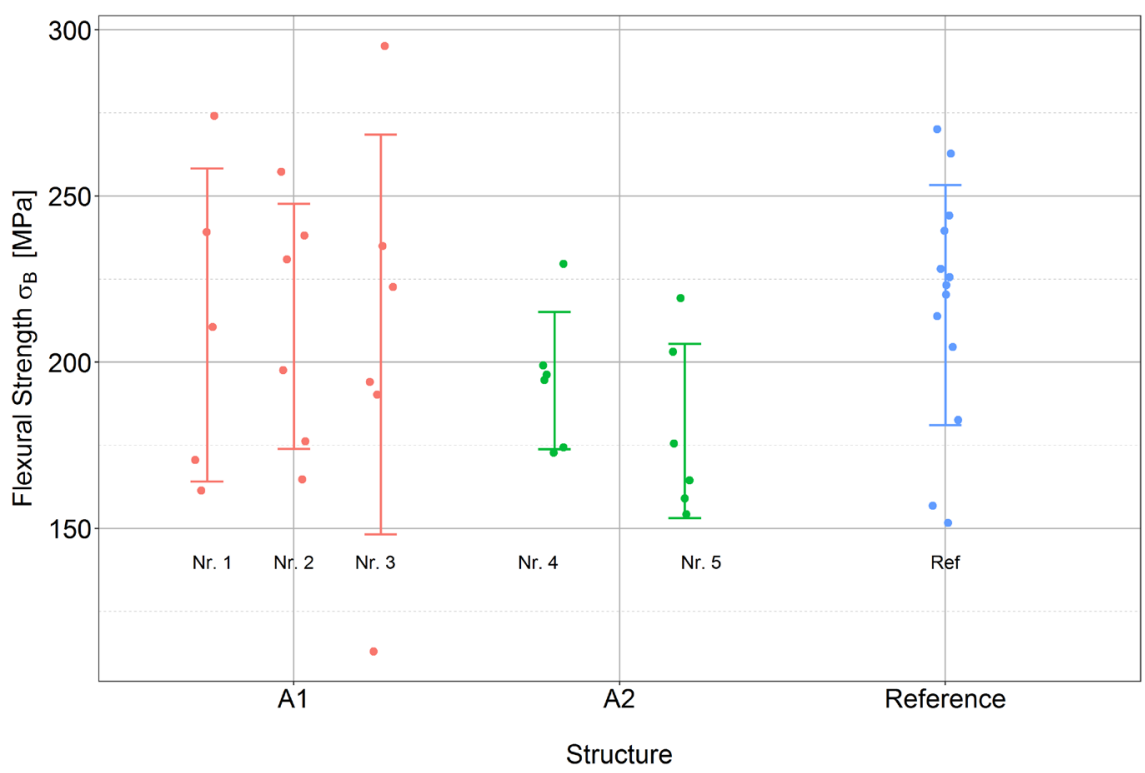

Figure 8. Bending flexural strength of laser treated LAS glass-ceramic samples compared to reference samples without laser treatment.

distribution inside the laser-induced area. The correlation between the isothermal lines for the melting point of LAS and the cross-section of the laser-modified area indicate that the crystal seeds are destroyed or displaced during the laser treatment.

The destruction or displacement of the crystal seeds inside the laser-modified area leads to the growth of longer and thicker $\beta$-spodumene crystals. The orientation of the crystals seems to be perpendicular to movement direction of the laser focus. A dependency of the size of these $\beta$-spodumene crystals and the bending flexural strength was proven in previous papers, but first four-point bending flexural tests showed that it was not possible to increase the flexural strength significantly, even if some samples reached good values.

\section{References}

[1] Cam, P., et al. (2015) A Novel Laser-Based Method for Controlled Crystallization in Dental Prosthesis Materials. Proceedings SPIE, 9306, 930607. https://doi.org/10.1117/12.2076567

[2] Schaffer, C.B. (2001) Interaction of Femtosecond Laser Pulses with Transparent Materials. Ph.D. Thesis, Harvard University Cambridge, Massachusetts.

[3] Mauclair, C., Memillod-Bolndin, A., Huot, N., Audouard, E. and Stoian, R. (2008) Ultrafast Laser Writing of Homogenous Longitudinal Waveguides in Glasses Using Dynamic Wavefront Correction. Optics Express, 16, 5481-5492. https://doi.org/10.1364/OE.16.005481

[4] Qiu, J., Miura, K. and Hirao, K. (1998) Three-Dimensional Optical Memory Using Glasses as a Recording Medium through a Multi-Photon Absorption Process. Japanese Journal of Applied Physics, 37, 2263-2266.

https://doi.org/10.1143/JJAP.37.2263

[5] Masuda, M., Sugioka, K., Cheng, Y., Aoki, N., Kawachi, M., Shihoyama K., Toyoda, 
K., Helvajian, H. and Midorikawa, K. (2003) 3-D Microstructuring inside Photosensitive Glass by Femtosecond Laser Excitation. Applied Physics A, 76, 857-860. https://doi.org/10.1007/s00339-002-1937-Z

[6] Miyamoto, I., Cvecek, K. and Schmidt, M. (2013) Crack-Free Conditions in Welding of Glass by Ultrashort Laser Pulse. Optics Express, 21, 14291-14302. https://doi.org/10.1364/OE.21.014291

[7] Johnston, T.F. (1998) Beam Propagation (M2) Measurement Made as Easy as It Gets: The Four-Cuts Method. Applied Optics, 37, 4840-4850. https://doi.org/10.1364/AO.37.004840

[8] Laczka, M., Laczka, K., Cholewa-Kowalska, K., Kounga, A.B. and Appert, C. (2013) Mechanical Properties of a Lithium Disilicate Strengthened Lithium Aluminosilicate Glass-Ceramic. Journal of the American Ceramic Society, 97, 1-4.

[9] Blombergen, N. (1974) Laser-Induced Electric Breakdown in Solids. IEEE Journal of Quantum Electronics, 10, 375-386. https://doi.org/10.1109/JQE.1974.1068132

[10] Calmano, T. (2013) Femtosekundenlasergeschriebene Kristalline Wellenleiterlaser im Sichtbaren und Nahen Infraroten Spektralbereich. Ph.D. Thesis, Universität Hamburg, Germany.

[11] Siebenmorgen, J. (2010) Herstellung von Wellenleiterlasern Mittels Femtosekunden-Laserstrukturierung in $\mathrm{Nd}$ - und Yb-Dotierten YAG-Kristallen. Ph.D. Thesis, Universität Hamburg, Germany.

[12] Miyamoto, I., Cvecek, K. and Schmidt, M. (2011) Evaluation of Nonlinear Absorptivity in Internal Modification of Bulk Glass by Ultrashort Laser Pulses. Optics EXpress, 19, 10714-10727. https://doi.org/10.1364/OE.19.010714

[13] Carslaw, H.S. and Jaeger, J.C. (2005) Conduction of Heat in Solids. 2nd Edition, Clarendon Press, Oxford.

[14] Miyamoto, I., Cvecek, K., Okamoto, Y., Schmidt, M. and Helvajian, H. (2011) Characteristics of Laser Absorption and Welding in FOTURAN Glass by Ultrashort Laser Pulses. Optics Express, 19, 22961-22973. https://doi.org/10.1364/OE.19.022961

[15] Sakaue, K., Yoneyama, S., Kikuta, H. and Takashi, M. (2008) Evaluating Crack Tip Stress Field in a Thin Glass Plate under Thermal Load. Engineering Fracture Mechanics, 75, 1015-1026. https://doi.org/10.1016/j.engfracmech.2007.04.025

[16] Shand, E.B. (1968) Engineering Glass, Modern Materials. Vol. 6, Academic Press, New York

[17] Anmin, H., Ming, L. and Dali, M. (2006) Preparation of Whisker $\beta$-Spodumene Glass-Ceramics. Journal of the American Ceramic Society, 89, 358-360. https://doi.org/10.1111/j.1551-2916.2005.00681.x 